
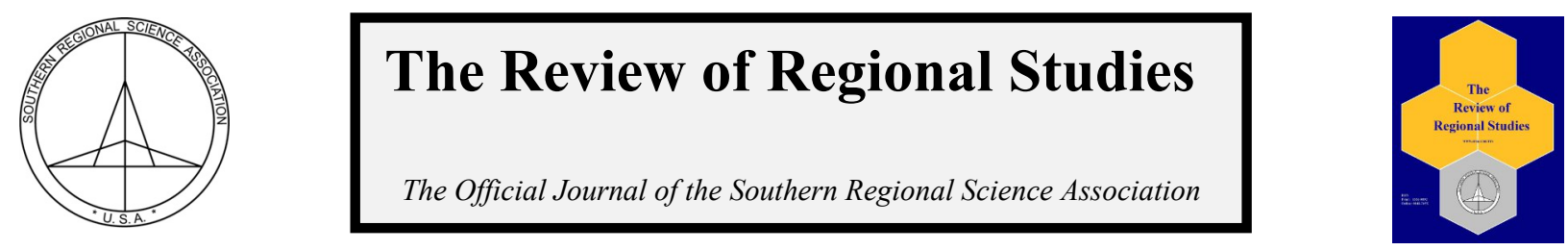

\title{
An LP-SAM Approach for Examining Regional Economic Impacts: An Application to Wildfire Disasters in Southeast Oregon
}

\author{
Man-Keun Kim ${ }^{\mathrm{a}}$, Erqian Zhu ${ }^{\mathrm{b}}$, Thomas R. Harris ${ }^{\mathrm{c}}$ and Jonathan E. Alevy ${ }^{\mathrm{d}}$ \\ ${ }^{a}$ Department of Applied Economics, Utah State University, USA \\ ${ }^{b}$ Department of Finance, Beijing Language and Culture University, China \\ ${ }^{c}$ Deparment of Economics, University of Nevada-Reno, USA \\ ${ }^{d}$ Department of Economics, University of Alaska-Anchorage, USA
}

\begin{abstract}
Assessment of regional economic impacts can be accomplished using either an input-output analysis or a social accounting matrix (SAM) analysis. While these approaches can generate important insights, they have significant limitations for some cases, e.g., the event of the need to reallocate limited resources such as land, labor, etc., because they do not include a complete set of decision makers' activities and managerial options. This study develops a flexible approach to link the firm level linear programming model to regional economic models to overcome these limitations, a LP-SAM. To demonstrate the LP-SAM a ranch-level economic model is linked to the regional SAM to investigate the impact of wildfire on the southeastern Oregon. The LP-SAM successfully traces out the decision makers' responses to wildfire and also regional economic impacts.
\end{abstract}

Keywords: linear programming, regional economic impact analysis, social accounting matrix, wildfire

JEL Codes: C61, C67, R15

\section{INTRODUCTION}

Assessment of regional economic impacts can be accomplished using either an inputoutput (IO) analysis that is based on the interrelationship among industries in the regional economy or a social accounting matrix (SAM) analysis that also values household sector impacts. These analyses are well known in regional economics and have long been applied to numerous economic issues and regional economic impact analyses. Regional economic impact analysis has been standardized using the IMPLAN microcomputer IO model (Minnesota IMPLAN Group, Inc., 2006). While both the IO and the SAM approaches can generate important insights, they have significant limitations for some types of studies, for example, in the event of the need to reallocate limited resources such as land, labor, machinery, etc.

Suppose that we are interested in investigating impacts of wildfire, especially wildfires on public grazing land in the western U.S. In cases of wildfire, ranchers may have restricted

\footnotetext{
*The authors thank the editors and referees for numerous helpful comments.

Kim is Assistant Professor in the Department of Applied Economics, Utah State University, Utah, USA. Zhu is Assistant Professor in the Department of Finance, Beijing Language and Culture University, Beijing, China. Harris is Professor in the Department of Economics, University of Nevada-Reno, Nevada, USA. Alevy is Assistant Professor in the Department of Economics, University of Alaska-Anchorage, Alaska, USA. Corresponding Author: M-K. Kim, E-mail: mk.kim@usu.edu
}

(C) Southern Regional Science Association 2013.

ISSN 1553-0892, 0048-749X (online)

www.srsa.org/rrs 
access to public grazing land. Limited access to public grazing land due to wildfire can have substantial economic impacts on a regional economy when public grazing is a major source of forage for the range cattle industry. This is the case in many regions of the Great Basin area (US Government Accountability Office, 2005, p. 61). To investigate the impacts of wildfire, we should consider a complete set of decision makers', i.e., ranchers' potential options including managerial responses to its occurrence. Measures of the change in sectoral output from wildfire in the standardized IO or SAM analyses are not sufficient to examine the regional economic impacts. Changes in herd size, changes in animal production mix and/or alternative forage sources, e.g., buying hay, are all potential responses to the occurrence of wildfire that are not amenable to analysis through the IO or SAM methodologies. This study develops a flexible approach to incorporate ranchers' potential responses to wildfire into the analysis of regional economic impacts.

To examine the regional economic impacts of this type of event, the IO or SAM model is integrated with a firm-level economic model that describes decision makers' responses including resource re-allocation to the event. The integration of the firm-level economic model with the SAM model is the main topic of the research. The model we construct measures economic impacts due to wildfire events that result in delayed grazing on burned areas; impacts that include the reduction of sectoral production, decreases in earnings and distributional changes in income across households in the region.

In short, the research goal of the study is to strengthen the theoretical approach to linking firm-level and regional economic models. For this study a ranch level linear programming (LP) model is linked to a regional SAM model that assesses the regional economic impacts from rangeland wildfires. We designate the integrated model the LP-SAM. The model is developed in the following three sections. The derivation of a general form of the LP-SAM is discussed in Section 2. Section 3 develops an empirical model with stochastic wildfire applied to a representative ranch in southeastern Oregon. Section 4 concludes the study.

\section{BASIC METHODOLOGIES}

\subsection{Firm Level Linear Programming Model}

Following neoclassical economic theory, the firm's objective is to maximize profit. The problem facing the firm is to decide how much output to produce to maximize profit given the technology, resource availabilities and (current) prices. The LP models are commonly used optimizing techniques applied to firm's decision making. The general form of the LP model for maximizing profit is:

$$
\begin{array}{cl}
\underset{\mathbf{z}}{\operatorname{Max}} & \mathbf{c}^{\prime} \mathbf{z} \\
\text { s.t. } & \mathbf{D z} \leq \mathbf{b}, \\
& \mathbf{z} \geq 0
\end{array}
$$

where $\mathbf{c}$ is a vector of the profit contribution (profit margin) of the activities, $\mathbf{z}$ is the vector of activities (decision variables), $\mathbf{D}$ is a matrix of technical coefficients of input used by the firm, and $\mathbf{b}$ is a vector of resource availabilities.

The solution of equation (1) derives the firm's net returns, quantity of each activity and production, the marginal cost of adopting alternative activities, and the value of having an additional unit of resource used (shadow price).

(C) Southern Regional Science Association 2013. 


\subsection{Input-Output Analysis and Social Accounting Matrix (SAM)}

The input-output (IO) model is based on the interrelationship between sectors in the economy and how each sector is affected by a change in the final demand for its output. For a regional economy of $n$ sectors the standard IO model is represented by $\mathbf{x}=\mathbf{y}+\mathbf{A x}$ or $(\mathbf{I}-\mathbf{A}) \mathbf{x}=$ $\mathbf{y}$, where $\mathbf{x}$ is an $n$-element vector of sector output, $\mathbf{y}$ is and $n$-element vector of the final demand, $\mathbf{I}$ is an $n \times n$ identity matrix, and $\mathbf{A}$ is an $n \times n$ direct requirement matrix.

Elements of matrix $\mathbf{A}, a_{i j}$, are calculated as $a_{i j}=x_{i j} / x_{j}$, where $x_{i j}$ is the transaction between sector $i$ and $j$, and $x_{j}$ is the sectoral output which is $x_{j}=\sum_{i} x_{i j}$. This relation indicates that the sum of output $\mathbf{x}$ equals to the direct uses in final demand $\mathbf{y}$ and its indirect uses in intermediate production Ax. A is called the direct requirements matrix and $(\mathbf{I}-\mathbf{A})$ the Leontief matrix. Provided the (I $-\mathbf{A})$ matrix is nonsingular, the above linear system can be solved for the amount of output necessary to support a given level of final demand as $\mathbf{x}=(\mathbf{I}-\mathbf{A})^{-1} \mathbf{y}$, where $(\mathbf{I}-\mathbf{A})^{-1}$ is called the Leontief inverse matrix. This relationship can be interpreted as $\Delta \mathbf{x}=(\mathbf{I}-\mathbf{A})^{-1} \Delta \mathbf{y}$, which means changes in total industry output are predicted using the Leontief inverse matrix. Thus the column sum of $(\mathbf{I}-\mathbf{A})^{-1}$ is interpreted as the total change in output due to changes in final demand. This value is called the output multiplier and is written as $\alpha^{\prime}=\mathbf{i}^{\prime}(\mathbf{I}-\mathbf{A})^{-1}$, where $\alpha$ is the output multiplier column vector and $\mathbf{i}$ is an $n \times 1$ column vector of ones. Thus, the $k^{\text {th }}$ element in $\alpha, \alpha_{k}$, is the total change in regional economic activity from a change in final demand by sector $k$. Using the multiplier, we analyze the regional economic impact from the (final demand) changes.

In the IO analysis, only the inter-industry linkages are formally specified. Industry transactions are read easily through the IO table. The linkages between household income and spending, government revenues and expenditure, and the linkage between saving and investment are not defined in the IO analysis. The Social Accounting Matrix (SAM) permits industry/household linkages to be specified with the same precision that inter-industry linkages are specified in the IO model. IMPLAN system provides for the construction of social accounting matrices at the regional level (MIG, 2006).

Following Holland and Wyeth (1993), the SAM model can be represented as:

$$
\left[\begin{array}{l}
\mathbf{x} \\
\mathbf{v} \\
\mathbf{h}
\end{array}\right]=\left[\begin{array}{l}
\mathbf{e x} \\
\mathbf{e v} \\
\mathbf{e h}
\end{array}\right]+\mathbf{S}\left[\begin{array}{l}
\mathbf{x} \\
\mathbf{v} \\
\mathbf{h}
\end{array}\right],
$$

where $\mathbf{S}$ is a matrix of SAM direct coefficients, analogous to $\mathbf{A}$ in the IO model, $\mathbf{x}$ is a vector of sector supply (row sum of activities or industries), $\mathbf{v}$ is a vector of value-added by categories (row sum of value-added), $\mathbf{h}$ is a vector of household incomes (row sum of households). ex, ev, eh are vectors of exogenous final demand, exogenous value added, and exogenous household income, respectively. The matrix of direct SAM coefficients, $\mathbf{S}$, is given by

$$
\mathbf{S}=\left[\begin{array}{ccc}
\mathbf{A} & \mathbf{0} & \mathbf{E} \\
\mathbf{V}^{*} & \mathbf{0} & \mathbf{0} \\
\mathbf{0} & \mathbf{Y}^{*} & \mathbf{H}
\end{array}\right],
$$

C Southern Regional Science Association 2013. 
where $\mathbf{A}$ is a matrix of input-output coefficients, $\mathbf{V}^{*}$ is a matrix of value-added coefficients, $\mathbf{Y}^{*}$ is a matrix of value-added distribution coefficients, $\mathbf{E}$ is a matrix of expenditure coefficients, and $\mathbf{H}$ is a matrix of institutional and household distributional coefficients. Equation (2) can be solved as

$$
\left[\begin{array}{l}
\mathbf{x} \\
\mathbf{v} \\
\mathbf{h}
\end{array}\right]=(\mathbf{I}-\mathbf{S})^{-1}\left[\begin{array}{l}
\mathbf{e x} \\
\mathbf{e v} \\
\mathbf{e h}
\end{array}\right],
$$

where $(\mathbf{I}-\mathbf{S})^{-1}$ represents the matrix of SAM inverse coefficients. The interpretation of $(\mathbf{I}-\mathbf{S})^{-1}$ is similar to the interpretation of $(\mathbf{I}-\mathbf{A})^{-1}$ in the IO model since the households and other institutional linkages are endogenous ${ }^{1}$. Using the SAM model and its multipliers, we can investigate regional economic impacts from the external shock to the exogenous sectors.

\subsection{Integrated Linear Programming and Social Accounting Matrix Model}

The mathematical integration of the LP model and SAM is accomplished simply by attaching diagonally the (I-S) matrix of the SAM to the D matrix of the LP in equation (1) (LPSAM model). Theoretical background to integrate LP and IO models is presented in Everett and McCarl (1976), Brink and McCarl (1977), and Bowker and Richardson (1989). The general form of the integrated model can be represented as:

$$
\begin{array}{rrr}
\underset{\mathbf{z}, \mathbf{x}}{\operatorname{Max}} & \multicolumn{1}{c}{\mathbf{c}^{\prime} \mathbf{z}+w} & \\
\text { s.t. } & \mathbf{D z} & \leq \mathbf{b} \\
-\mathbf{P z}+(\mathbf{I}-\mathbf{S}) \mathbf{x} & \leq \mathbf{y}^{0}, \\
\mathbf{i}^{\prime} \mathbf{x} & =w \\
\mathbf{z}, \mathbf{x}, w & \geq 0
\end{array}
$$

where $\mathbf{P}$ is a matrix of firm's per unit intermediate demand or the amount of intermediate good required of the industries in the region for each unit of activity. The vector $\mathbf{x}$ in equation (5) indicates the regional industry outputs ( $\mathbf{x}, \mathbf{v}$, and $\mathbf{h}$ in equation (4)), $\mathbf{S}$ is a matrix of SAM direct coefficients, and $\mathbf{y}^{0}$ is a vector of exogenous final demand, value added and household income (ex, $\mathbf{e v}$ and $\mathbf{e h}$ in equation (4)). $\mathbf{i}$ is the column vector of ones and thus, $w$ is the total regional output scalar. The objective function is the sum of firms' profit and the value of regional output.

An element of the $\mathbf{P}$ matrix, $p_{i, m}$, is the per unit intermediate good required of the $m^{\text {th }}$ activity, $z_{m}$, in the LP model from the $i^{\text {th }}$ industry, which captures the corresponding interindustry feedback between the LP model and the SAM. In words, firm's $m^{\text {th }}$ activity, $z_{m}$, requires $p_{i, m}$ worth of output from the $i^{\text {th }}$ industry to produce or perform one unit of $z_{m}$. They are obtained by modifying the SAM coefficients, $s_{i, j}$, in the $\mathbf{S}$ matrix, where $i$ and $j$ are sectors in the SAM model. This process may be represented by using equation (6):

\footnotetext{
${ }^{1}$ IO analysts make a distinction between Type I and Type II multipliers. The Type I multiplier, $\mathbf{i}^{\prime}(\mathbf{I}-\mathbf{A})^{-1}$, summarizes the relationship between the direct and indirect effects. The Type I multiplier is calculated as (direct + indirect effects)/(direct effect). The Type II multiplier, $\mathbf{i}^{\prime}(\mathbf{I}-\mathbf{S})^{-1}$ includes the impact of consumption-induced effects, capturing the effects of household spending on regional economy. The Type II multiplier is calculated as (direct + indirect + induced effects)/(direct effect).
}

(C) Southern Regional Science Association 2013. 


$$
p_{i, m}=\frac{s_{i, j} \cdot \mathrm{GVP}_{m}}{\mathrm{GVP}_{j}}(i \neq j) j=\text { industry where the firm is classified in SAM }
$$

where GVP is the gross value of product defined as $\mathrm{GVP}_{m}=c_{m} z_{m}$, where $c_{m}$ is the profit contribution, $m^{\text {th }}$ element in the vector $\mathbf{c}$ in equation (1) or (5), of the activity $m$. To calibrate $p_{i, m}$ the reference levels of $z_{m}$ are utilized.

\section{EMPIRICAL MODEL}

Equation (5) is the general form of the LP-SAM model. In this section, the empirical LPSAM model is derived to assess wildfire impacts on the regional economy of southeast Oregon. The management of public grazing land in the context of wildfire is discussed in the subsections that follow.

\subsection{Public Grazing Land and Wildfire}

Modeling, measuring, and managing public grazing land and wildfire risk are essential and challenging tasks for rangeland managers in the western U.S., especially in the Great Basin area, where the invasion of cheatgrass increases the risk of wildfire (Knapp, 1998; Link et al., 2006). Following a wildfire, ranchers' access to public grazing land is restricted, typically for two years ${ }^{2}$. Limited access to public grazing land due to wildfire has substantial economic impacts on the regional economy because public grazing is a major source of forage for cattle and thus an important input for ranching businesses in areas that are heavily dependent upon public lands for seasonal or year-round forage resources (many regions of the Great Basin area) (US Government Accountability Office, 2005, p. 61). The LP-SAM model in equation (5) is used to investigate the wildfire damage in terms of the regional economic losses from delayed grazing on burned areas. Firstly a ranch level LP model is introduced.

\subsection{A Ranch Level Dynamic Linear Programming Model}

The rancher's behavior can be modeled using the LP model as in equation (1). The objective of a ranch manager is to maximize the sum of discounted profits over a T-year planning horizon subject to resource availabilities, public grazing allotment quantities, input and output prices, and resource transfers between periods (especially breeding cows). The LP model considers almost all of rancher's decision variables in the typical western US ranches including seasonal forage supply and demand. The model is a discrete-time optimal control problem.

Let $z_{m, t}$ denote rancher's decision variables at the time $t$, where $m=$ herd size (ctt)), cattle sales (sell), forage usages (pblc, prvt), other resource uses, and so on. Let $z_{c t t l, t}$ denote the herd size at the beginning of year $t$. Herd dynamics are represented as:

$$
z_{c t t l, t+1}=(1+\beta) z_{c t t l, t}-z_{\text {sell,t }},
$$

where $\beta$ is the net reproduction rate including death rate and $z_{\text {sell, }, t}$ is cattle sales at the time $t$. Both the herd-size and cattle-sales variables in the model contain different classes of cattle differentiated by age and sex. For simplicity of presentation, animals of different age-sex classes are not differentiated. Suppose that the rancher has the public grazing land, $z_{p b l c, t}$ as described in equation (8):

\footnotetext{
${ }^{2}$ For public land management agencies, delaying grazing on burned areas for a minimum of 2 years is the standard policy. Bruce et al. (2007) pointed out that "the 2-year grazing moratorium" has not been validated by research.
}

(C) Southern Regional Science Association 2013. 


$$
z_{p b l c, t} \leq\left(1-f_{t}\right) L_{t}
$$

where $L_{t}$ is the total public grazing land area available in year $t . L_{t}$ is influenced by wildfire, $f_{t}(0$ or 1). When $f_{t}=0$, there is no wildfire and all the grazing land is available to the rancher, i.e., $z_{p b l c, t}=L_{t}$. When $f_{t}=1$, there is a fire and all the public grazing is delayed for two years.

The rancher has other resources such as purchasing pasture or hay, and other types of rangelands, e.g., private land. For simplicity of presentation, assume that the rancher owns only private rangeland, and it is given by

$$
z_{p r v t, t} \leq b_{p r v t, t},
$$

where $z_{p r v t, t}$ is the private rangeland and $b_{p r v t, t}$ is the amount of private rangeland the rancher owns. The herd size, without supplementary feeding during the grazing season, in a given year is limited by the available forage from both public grazing land and private rangeland. Especially, in the Great Basin area ${ }^{3}$, the role of public grazing land is crucial. The forage balance equation is set as

$$
-\delta_{1} z_{c t t l, t}+\delta_{2} z_{p b l c, t}+\delta_{3} z_{p r v t, t} \leq 0
$$

where $\delta_{1}$ is the forage requirement per cattle, and $\delta_{2}$ and $\delta_{3}$ are carrying capacity per acre of public and private rangelands per acre, respectively.

In addition, there exist other resource constraints to labor, machines, and working capital. The constraints can be implemented using standard LP restrictions, and are not explicitly listed. Thus, the profit $(\pi)$ is comprised of revenue from cattle sales and costs of the herd maintenance and rangelands such that

$$
\pi_{t}=c_{1} z_{\text {sell }, t}-c_{2} z_{\text {cttl }, t}-c_{3} z_{p b l c, t}-c_{4} z_{p r v t, t},
$$

where $c_{1}$ is the cattle sales price, and $c_{2}, c_{3}$, and $c_{4}$ are corresponding cost parameters.

Finally, assuming risk-neutrality, the rancher's decision problem is given by

$$
\operatorname{Max}_{z_{m}} \sum_{t=0}^{T}(1+r)^{-t} \pi_{t} \text {, s.t. (7),(8), (9), (10)and (11), }
$$

where $r$ is the proper discount rate. Note that the actual LP model has additional constraints that describe ranch operations.

The solution of the ranch LP model provides following information on ranch activities:

- Production and sales: cattle sold, alfalfa hay sold

- Resource usage: quantity of each resource used and unused (such as public land grazing permits)

- Value of financial activities: principal and interest payments and repayment of a shortterm loan.

The LP model has the flexibility to alter parameters and provides the results on either an annual basis, or for inputs for which it is relevant, such as federal $\mathrm{AUMs}^{4}$, on a seasonal basis.

\footnotetext{
${ }^{3}$ To the rest of the U.S., private land tends to determine herd size.

${ }^{4} \mathrm{AUM}=$ the animal unit month is "the most widely used way to determine the carrying capacity of grazing animals on rangelands." One AUM is the amount of forage that a $1000 \mathrm{lb}$ cow with calf eats in one month, roughly $800 \mathrm{lbs}$ of forage on a dry weight basis (Pratt and Rasmussen, 2001).
}

(C) Southern Regional Science Association 2013. 
The LP model is calibrated using the Oregon cow-calf budget data and also a referenced study by Maher (2007).

\subsection{Integrated Linear Programming and Social Accounting Matrix Model}

To derive distributional impacts of wildfire on the regional economy, the ranch level LP model should be integrated to the SAM model. The LP-SAM model provides the regional direct, indirect and induced effects of changes in sector outputs (changes in output in cattle sector due to the wildfire). In addition, the LP-SAM model can generate changes in employment as well as income distribution in the region.

The integrated model is written by:

$$
\begin{array}{ll}
\underset{z_{m, q}, x_{i}}{\operatorname{Max}} & {\left[\sum_{t} \sum_{q}(1+r)^{-t} \pi_{q, t}+\sum_{t}(1+r)^{-t} w_{t}\right]} \\
\text { s.t. } & \pi_{q, t}=c_{1 q} z_{\text {sell, }, t}-c_{2 q} z_{c t t l, q, t}-c_{3 q} z_{p b l c, q, t}-c_{4 q} z_{p r v t, q, t} \\
& z_{c t t l, q, t+1}=(1+\beta) z_{c t t l, q, t}-z_{\text {sell, }, t} \\
& z_{p b l c, q, t} \leq\left(1-f_{q, t}\right) L_{q, t} \\
& z_{p r v t, q, t} \leq b_{p r v t, q, t} \\
& -\delta_{1} z_{c t t l, q, t}+\delta_{2} z_{p r v t, q, t}+\delta_{3} z_{p b l c, q, t} \leq 0 \\
& -\sum_{q} z_{\text {sell, }, t}+x_{c t t l, t} \leq 0 \\
& \mathbf{i}^{\prime} \mathbf{x}_{t}=w_{t} \\
& -\mathbf{P z}_{t} \quad+(\mathbf{I}-\mathbf{S}) \mathbf{x}_{t} \leq \mathbf{y}^{0} \\
& \mathbf{z}_{t}, \mathbf{x}_{t}, w_{t} \geq 0
\end{array}
$$

where $q$ is a ranch index and thus $\pi_{q, t}$ is the profit for the ranch $q$ at the time $t$. Index $i$ represents the economic sectors in SAM account and $x_{i, t}$ is the sectoral output. Similar to equations (7) to (11), the profit, herd dynamics, rangeland restrictions, and forage balance equation are given in equation (13).

Inter-industry constraints are required to integrate the LP and the SAM. From the LP, the production of cattle is transferred to the SAM that consists of the production of ranching-cattle sector. The regional cattle production is simply the sum of rancher's cattle sales, that is, $\sum_{q} z_{\text {sell, }, t,} \geq x_{c t l l, t}$. In addition, the matrix $\mathbf{P}$ in equation (13) is constructed using equation (6). In equation (13), the vectors $\mathbf{z}$ and $\mathbf{x}$ are $\mathbf{z}^{\prime}=\left\lfloor z_{\text {sell, },}, z_{c t t l, t}, z_{p b l c, t}, z_{p r v t, t}\right\rfloor$, and $\mathbf{x}^{\prime}=\left[x_{i, t}\right]$. $\mathbf{S}$ is a matrix of SAM direct coefficients, and $\mathbf{y}^{0}$ is a vector of exogenous final demands. The objective function is the sum of ranchers' profit and the value of regional output.

Note that, in the empirical application, we assume that ranches in the region are identical. This assumption allows us to aggregate ranches' activities into a single representative ranch. We can then drop the ranch index $q$ from equation (13) by defining $\sum_{q} z_{m, q, t}=z_{m, t}, \sum_{q} L_{q, t}=L_{t}$, and $\sum_{q} b_{p r v t, q, t}=b_{p r v t, t}$. In addition, we drop the ranch index, $q$, from $f_{q, t}$. 
The $\mathbf{S}$ matrix and corresponding parameters in equation (13) can be calibrated using the IMPLAN database. Aggregation of the study area data in IMPLAN is based on 2 digit NAICS (North American Industry Classification System) code, with the following exception; cattle and hay sectors are disaggregated and to be distinct from other agriculture activities. After the aggregation, a SAM table can be generated by IMPLAN. See Table 1 for the sector aggregation.

\subsection{Stochastic Wildfire}

The public grazing allotment for ranchers, $L_{t}$, is affected by wildfire as in equation (13), $z_{p b l c, t} \leq\left(1-f_{t}\right) L_{t}$, which puts a constraint on the cattle stock, $-\delta_{1} z_{c t t l, t}+\delta_{2} z_{p b l c, t}+\delta_{3} z_{p r v t, t} \leq 0$. Note that wildfire size and public grazing land do not have $q$ subscripts. Also note that $f_{t}$ is not simply 0 or 1 but $0 \leq f_{t} \leq 1$ at the regional level. In addition, $f_{t}$ at the regional level is stochastic in nature thus $f_{t}$ should be generated randomly to run the LP-SAM model. This section explains how to generate $f_{t}$ randomly.

In year $t$, ranchers will be limited to a portion of public grazing land by $\widetilde{f}_{t}$ which is defined by:

$$
\widetilde{f}_{t}=\left(\widetilde{B}_{t}+B_{t-1}\right) / \bar{L}_{t},
$$

where $\bar{L}_{t}$ is the public grazing land in the region (around 1.5 million acres in the study area, southeast Oregon, from Agricultural Census 2007 and US GAO (2005)), and $\widetilde{B}_{t}$ is the stochastic burned area where the ranchers are not allowed to graze. Note that tilde on variables

Table 1: Aggregation for Economic Sectors

\begin{tabular}{|c|c|c|}
\hline Sector & IMPLAN Sectors & \\
\hline Agriculture & $1-10,12-14,15-19$ & \multirow{9}{*}{$\begin{array}{l}\text { Activities } \\
(\mathbf{x})\end{array}$} \\
\hline Hay & 10 & \\
\hline Cattle-Ranching & 11 & \\
\hline Mining & $20-30$ & \\
\hline Utilities & $31-33$ & \\
\hline Construction & $34-40$ & \\
\hline Manufacture & $41-318$ & \\
\hline Trade & $319-340$ & \\
\hline Service & $341-440$ & \\
\hline Employee Compensation & 5001 & \multirow{4}{*}{$\begin{array}{l}\text { Value } \\
\text { Added (v) }\end{array}$} \\
\hline Proprietary Income & 6001 & \\
\hline Other Property Type Income & 7001 & \\
\hline Indirect Business Taxes & 8001 & \\
\hline Households LT10k & 10001 & \multirow{9}{*}{$\begin{array}{l}\text { Households } \\
\text { (h) }\end{array}$} \\
\hline HH $10-15 \mathrm{k}$ & 10002 & \\
\hline HH $15-25 k$ & 10003 & \\
\hline HН $25-35 k$ & 10004 & \\
\hline HH $35-50 k$ & 10005 & \\
\hline HH 50-75k & 10006 & \\
\hline HН 75-100k & 10007 & \\
\hline HH $100-150 \mathrm{k}$ & 10008 & \\
\hline $\mathrm{HH} 150 \mathrm{k}+$ & 10009 & \\
\hline
\end{tabular}

(C) Southern Regional Science Association 2013. 
indicate that they are stochastic. $B_{t-1}$ is added to the computation of the random fire size because the ranchers may not access to the public grazing land for two years.

The stochastic burned area is calculated as $\widetilde{B}_{t}=\widetilde{F}_{t} \cdot \widetilde{N}_{t}$, where the variable $F_{t}$ represents the wildfire size and $N_{t}$ number of wildfire in the region. The number of wildfire and the fire size are generated randomly as follows:

$$
\widetilde{F}_{t}=\bar{F}_{t}+\widetilde{e}_{1 t} \text { and } \widetilde{N}_{t}=\bar{N}+\widetilde{e}_{2 t}
$$

where $\widetilde{e}_{1 t}$ and $\widetilde{e}_{2 t}$ are the pure stochastic parts and are assumed to follow the normal distribution with mean zero. The fire size and the number of wildfires are correlated (historical data in the study region, southeast Oregon, show that the correlation is 0.58 with the t-value of 2.3). Thus, when we generate a random $\widetilde{e}_{1 t}$ and $\widetilde{e}_{2 t}$, intra-correlation should be considered as suggested by Richardson, Klose and Gray (2000). Random $\widetilde{e}_{1 t}$ and $\widetilde{e}_{2 t}$ are simulated as following:

$$
\left[\begin{array}{c}
\widetilde{e}_{1 t} \\
\widetilde{e}_{2 t}
\end{array}\right]=\left[\begin{array}{cc}
1 & \rho_{12} \\
& 1
\end{array}\right]\left[\begin{array}{l}
\varepsilon_{1} \\
\varepsilon_{2}
\end{array}\right],
$$

where $\varepsilon$ 's are independent disturbances from the normal distributions, and $\rho$ 's are correlation coefficients. Using equations (14), (15) and (16) and the Monte Carlo simulation, $\widetilde{f}_{\mathrm{t}}$, in the near future is generated.

From the ranchers' perspective, however, $\widetilde{f}_{t}$ is not known for sure before making the production decisions. Ranchers are not in a position to respond optimally to the stochastic wildfires. In the applied example, thus, the confidence bands are constructed by allowing burns to be realized in the first year and computing responses for the future horizon using expected burned areas conditioned on events of the first year. Then, burns are realized for the second year, and responses computed for the remainder of the horizon using expected burn areas in future years conditioned on events of the first two years. This process is continued until the end of the planning horizon and burns realized in the last year.

\subsection{Applied Example: Southeast Oregon}

\subsubsection{Study Areas and Wildfires}

Southeastern Oregon was selected as the study area to demonstrate the application of the LP-SAM. The study area is located on the northern edge of the Great Basin area (Figure 1). Because of geological characteristics, this area has a higher temperature than the national average and lower amount of rainfall than the national average (NOAA, 2011). As a consequence, this area has frequent wildfire occurrences.

Four counties are included in the study area: Lake, Harney, Klamath and Malheur. The area is approximately 22 million acres which accounts for about 35\% of Oregon's land mass. These four counties' economies are based on the cattle ranching and farming sectors (Cornelius et al., 2000). In 2006, the cattle ranching and farming sectors recorded an output of $\$ 258$ million (calculated from IMPLAN database for 2006) which was $4.3 \%$ of the total value of the regional output, placing this sector fifth among the regions' 191 economic sectors. This area was chosen as the study area because i) cattle-ranching business in the region is a major business sector, ii)

(C) Southern Regional Science Association 2013. 
Figure 1: Southeast Oregon: Klamath, Lake, Harney, and Malheur Counties
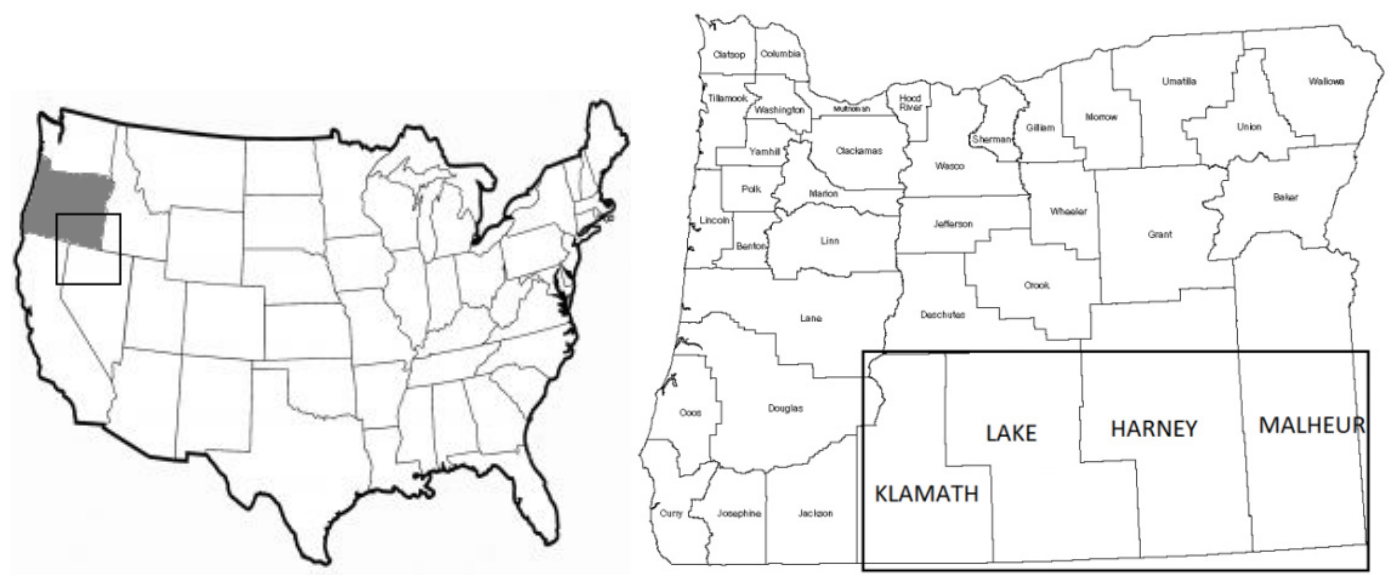

public grazing land is the key source of forage for ranchers, iii) frequent wildfires limit the access to the public grazing land, and iv) the ranch-level LP model is fully calibrated for a representative ranch in Maher (2007).

Wildfire data for the region is collected from the National Fire and Aviation Management website maintained by National Interagency Fire Center (https://fam.nwcg.gov/fam-web/). Figure 2 shows, in bars, the number of wildfires during $1999-2010$. On average 17 wildfires occurred each year in the region. The number of wildfires peaked in 2006 (38 occurrences). The number of wildfires has a positive trend over time (correlation between the number of wildfires and the time trend is 0.35 with t-value 1.2). The average burned area per fire or wildfire size is reported as 4,665 acres per fire per year and it fluctuates widely. The wildfire size peaked in 2007 (15,390 acres). Figure 2 presents wildfire size as a solid line. Wildfire size also has a positive trend over time but the relationship is not statistically significant (correlation between the fire size and time trend is 0.02 . and t-value is 0.08 ).

The average projected area burned, $\widetilde{B}_{t}$, ranged from 76,687 acres to 103,593 acres. The acreages are equivalent to roughly $7.5 \%$ to $13.4 \%$ of the public grazing land in the region that would not be available to ranchers.

\subsubsection{Results and Discussion}

The LP-SAM model simulates outputs over a 15-year period (and reports 5 years of results to avoid biases from any terminal conditions) assuming constant animal sales price and forage cost per AUM on public land for simplicity. In addition, we assume that the number of ranches will not change for the duration of the simulation period. The LP-SAM model is iterated 5,000 times, and the expected burn area 1,000 times with stochastic wildfires that allow us to generate the distribution of annual economic impacts (average and standard deviation). The General Algebraic Modeling System (GAMS) with BDMLP solver is used to run the model. 


\section{Figure 2: Number of Wildfires and Size in Southeast Oregon Area (4 Counties)}

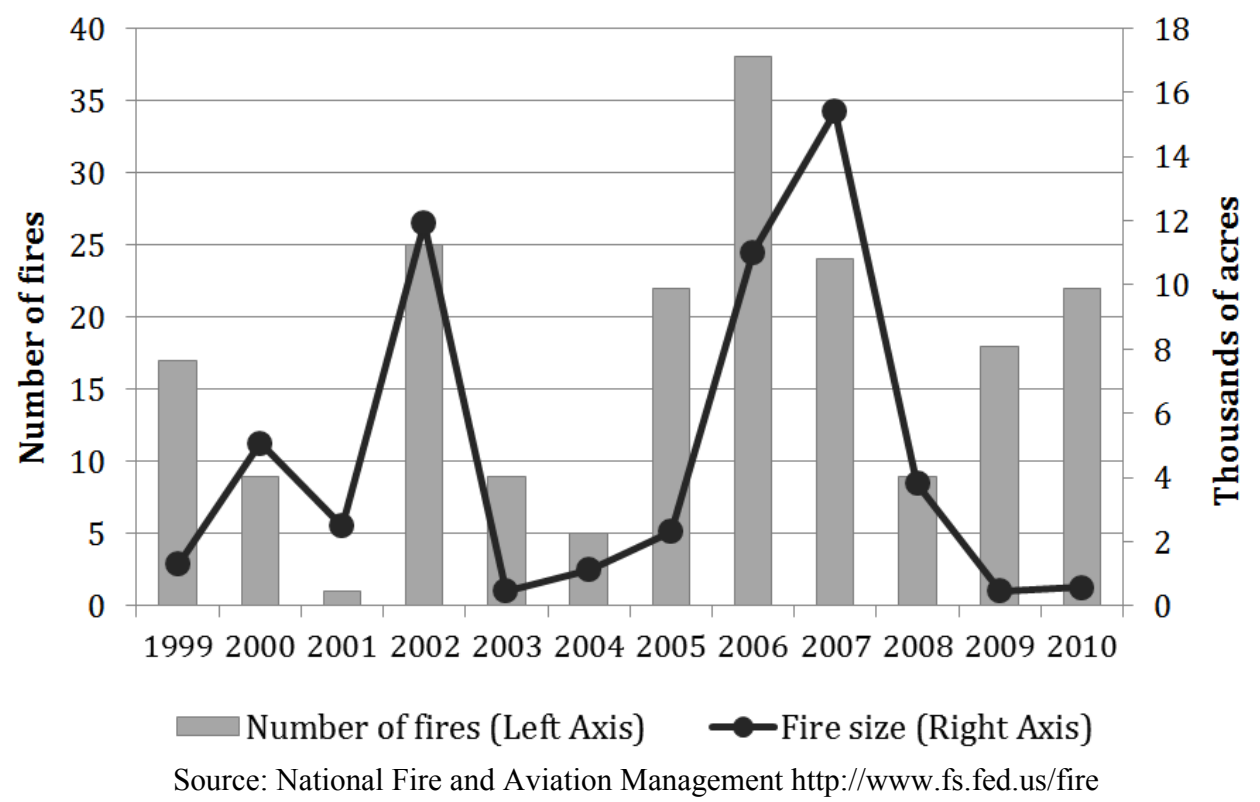

Figure 3 presents the four major sectors which face the largest economic losses: cattle, service, agriculture $\&$ hay sectors, and manufacturing and trade sectors. The finding stresses that spillover outside the cattle sector is important - a result which should be relevant to policy makers. The loss is the difference between the value of production in 2006 (calibrated from IMPLAN) and the value of production under the conditions generated by the wildfire simulation $^{5}$. The loss from the cattle sector varies from \$0.6 million to \$2.4 million, depending on the size of the wildfire (see Figure 3 Loss in Cattle Sector; dot lines are 95\% confidence band). The loss from the agriculture and hay sectors varies from $\$ 0.1$ million to $\$ 0.5$ million. The loss from the service sector varies from $\$ 0.2$ million to $\$ 1$ million which is caused by the interrelationship among industries in the regional economy.

Note that the loss appears to level out after a couple of years. This occurs because the random wildfires in first two years are conditioned on the historical wildfires in years 2009 and 2010, which were relatively small (see Figure 2). Thus, the new wildfire equilibrium, after a couple of years, would yield the expected regional impacts from wildfire.

Table 2 and Figure 4 show the economic impact in the region including direct and indirect economic losses from the wildfire using the SAM structure. In figure 4, the primary sector includes agriculture, hay and mining. The secondary sector includes utilities, construction, and manufacturing. The tertiary sector is the sum of trade and service sectors. The cattle sector receives the largest regional impact from wildfire - $\$ 1.95$ million per year on average. The hay sector loses an average of $\$ 0.27$ million annually, and the agriculture sector loses $\$ 0.15$ million annually.

\footnotetext{
5 The value of production in 2006 is not a reference level without wildfire. It is a level that has already adjusted to the wildfire outbreaks that are common in the study region. To make the value of production in 2006 the reference level, the stochastic wildfire, $\widetilde{f}_{t}$, is adjusted for the simulation such that $\widetilde{f}_{t}=\left(\left(\widetilde{B}_{t}+B_{t-1}\right) / \bar{L}_{t}\right) / f_{2006}$.
} 
Figure 3: Losses in Selected Economic Sectors from Wildfires in Southeast Oregon Loss in Cattle Sector Loss in Service Sector
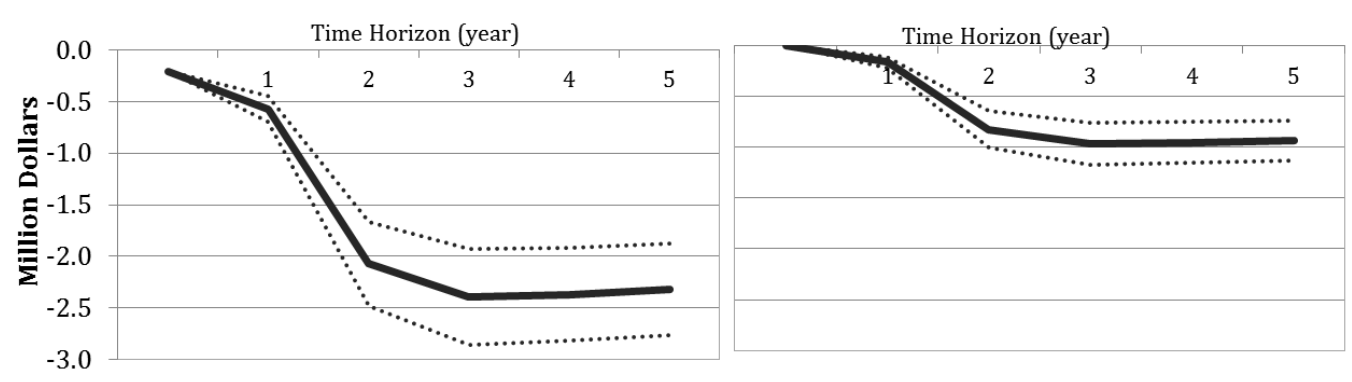

Loss in Agriculture and Hay Sector

Loss in Manufact. \& Trade Sectors
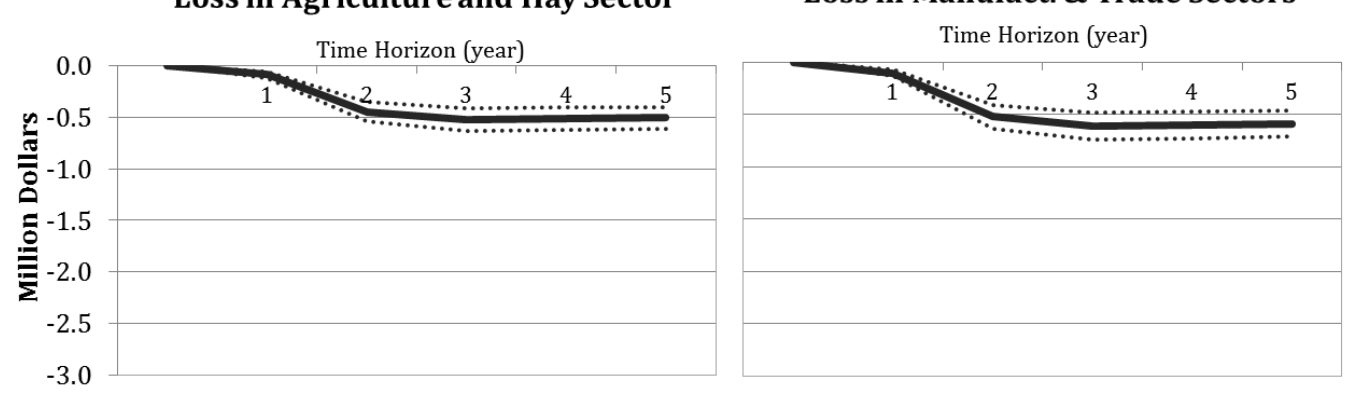

Note: Loss is the difference between the value of production in 2006 and the value of production under wildfires in the near futures. Dotted lines are 95\% confidence bands from 5,000 simulations.

Table 2: Regional Economic Impacts - Reduction of Value of Production (5 yr. Avg.)

\begin{tabular}{|c|c|c|}
\hline \multicolumn{2}{|r|}{ Sector } & Direct and Indirect Loss (\$million) \\
\hline Activities & Agriculture & 0.147 \\
\hline \multirow{8}{*}{$(\mathrm{X})$} & Hay & 0.268 \\
\hline & Cattle & 1.946 \\
\hline & Mining & 0.000 \\
\hline & Utilities & 0.035 \\
\hline & Construct & 0.013 \\
\hline & Manufacturing & 0.312 \\
\hline & Trade & 0.173 \\
\hline & Service & 0.767 \\
\hline \multicolumn{2}{|l|}{ Activities total } & 3.662 \\
\hline \multirow{4}{*}{$\begin{array}{l}\text { Value Added } \\
\text { (V) }\end{array}$} & Employee Compensation & 0.628 \\
\hline & Proprietary Income & 0.079 \\
\hline & Other Property Type Income & 0.330 \\
\hline & Indirect Business Taxes & 0.095 \\
\hline \multicolumn{2}{|c|}{ Value added total } & 1.133 \\
\hline \multirow[t]{2}{*}{ Households } & Less than $10 \mathrm{k}$ & 0.012 \\
\hline & $10 \mathrm{k}$ to $15 \mathrm{k}$ & 0.021 \\
\hline \multirow[t]{7}{*}{$(\mathrm{HH})$} & $15 \mathrm{k}$ to $25 \mathrm{k}$ & 0.065 \\
\hline & $25 \mathrm{k}$ to $35 \mathrm{k}$ & 0.081 \\
\hline & $35 \mathrm{k}$ to $50 \mathrm{k}$ & 0.125 \\
\hline & $50 \mathrm{k}$ to $75 \mathrm{k}$ & 0.191 \\
\hline & $75 \mathrm{k}$ to $100 \mathrm{k}$ & 0.090 \\
\hline & $100 \mathrm{k}$ to $150 \mathrm{k}$ & 0.062 \\
\hline & $150 \mathrm{k}$ plus & 0.048 \\
\hline \multicolumn{2}{|c|}{ Households total } & 0.695 \\
\hline
\end{tabular}

(C) Southern Regional Science Association 2013. 
The service sector is another sector which suffers a large impact from wildfire. The annual loss is reported as $\$ 0.77$ million. The losses in the service sector come from the interrelationships between the cattle sector and the service sector, for example, cattle and meat transportation, restaurants, grocery stores and so on. The manufacturing sector experiences $\$ 0.31$ million loss annually, probably due to the reduction in the manufacturers relating to livestock, hay and agriculture. In total, regional output decreases by $\$ 3.66$ million (activities total) annually. Table 2 also contains the institutional impact from the wildfire. Employee compensation (wage and salary) is reduced by $\$ 0.63$ million and indirect business taxes by $\$ 0.10$ million. Income class, $35 \mathrm{k}$ to $50 \mathrm{k}$, loses $\$ 0.13$ million and $50 \mathrm{k}$ to $75 \mathrm{k}, \$ 0.19$ million.

In short, Southeastern Oregon (four counties) may lose $\$ 3.66$ million annually on average from wildfires (with estimates varying from $\$ 0.94$ million to $\$ 4.56$ million) (Figure 4 ). The most vulnerable sectors are the cattle sector and tertiary sectors in the region. It should be noted that these values are conservative estimates because additional losses, such as environmental and ecological effects, reductions in recreational access, direct wildfire suppression costs and so on, are not considered.

\section{CONCLUSION AND FUTURE RESEARCH}

In this study, the LP-SAM model - an integration of the firm-level LP model with the SAM - is developed to investigate regional economic impacts from various events. The LP-SAM is flexible enough to investigate the regional economic impacts with the complete set of firmlevel decision making to the exogenous shocks, i.e., wildfire in the public grazing land. For a demonstration, we construct the LP-SAM model for Southeast Oregon area where the cattleranching business is the major sector. The LP-SAM successfully traces out the ranch managers' responses to wildfire on public grazing land and also regional economic impacts as discussed in the above sections.

Figure 4: Regional Economic Impact from Wildfires in Southeast Oregon

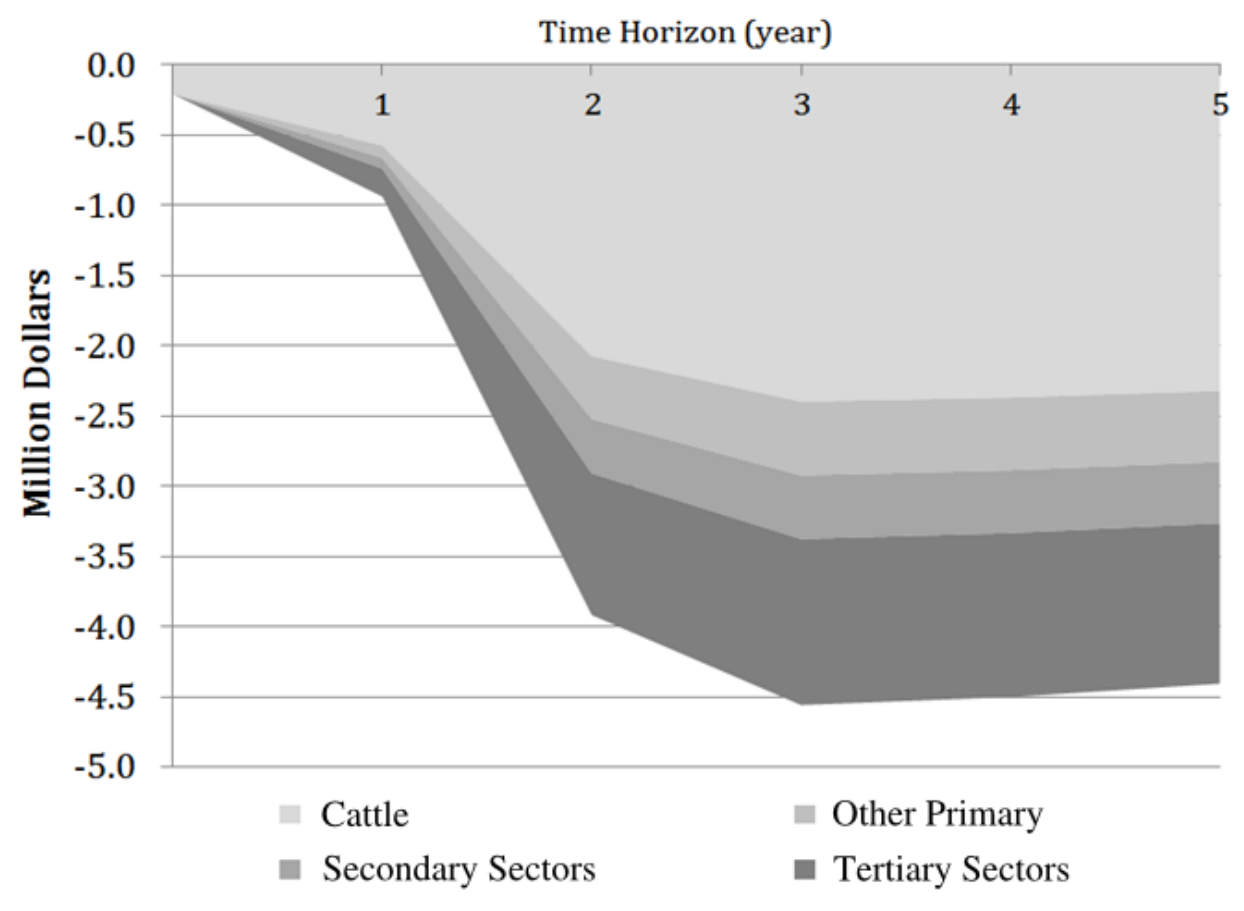

(C) Southern Regional Science Association 2013. 
The LP-SAM is essentially a spatial modeling approach and it could be extended to a multiregional IO model (MRIO formulation) to deal with trade flows between the sub-regions involved. The IMPLAN database offers the trade flow data between regions, and thus developing a multiregional LP-SAM model is one area of potential future research.

Two caveats should be mentioned with respect to the LP-SAM demonstration. First, regarding the way we construct the expected wildfire occurrences; we assume that ranchers build their expectations from historical observations of wildfire. This might be too simple a model of expectation formation. Second, the single ranch assumption does not permit us to investigate substitution effects. It is plausible that the large commercial ranchers are not as vulnerable to delayed grazing on burned area as small ranchers. In addition, some of the small ranchers may go bankrupt under severe wildfire. Some degree of substitution, in which the large commercial ranchers produce more, is expected. The model used in the study may not detect this possibility. The future plan for this study introduces heterogeneity in rancher type into the analysis.

\section{REFERENCES}

Brink, Lars and Bruce A. McCarl. (1977) "Input-output Analysis, Linear Programming and the Output Multiplier," Canadian Journal of Agricultural Economics 25(3):62-67.

Bruce, Ben, Barry Perryman, Ken Conley, and Kent McAdoo. (2007) "Case Study: Grazing Management on Seeded and Unseeded Post-fire Public Rangelands," The Professional Animal Scientist 23:285-290.

Bowker, Michael and James Richardson. (1989) "Impacts of Alternative Farm Policies on Rural Communities,” Southern Journal of Agricultural Economics 21:33-46.

Cornelius, Jim, David Holland, Edward Waters, and Bruce Weber. (2000) "Agriculture and the Oregon Economy,” Special Report 1014, Oregon State University Extension Service.

Everett, Hal and Bruce McCarl. (1976) "Regional Economic Planning: A Methodology for Integrating Linear Programming and Input-Output Analysis," Journal Paper Number 5798, Purdue Agricultural Experiment Station.

Holland, David and Peter Wyeth. (1993) "SAM Multipliers: Their Decomposition, Interpretation and Relationship to Input-Output Multipliers," Research Bulletin XB 1027, College of Agriculture and Home Economics Research Center, Washington State University

Knapp, Paul. (1998) "Spatio-temporal Patterns of Large Grassland Fires in the Intermountain West U.S.A.” Global Ecology and Biogeography Letters 7:259-272.

Link, Steven, Carson Keeler, Randal Hill, and Erick Hagen. (2006) "Bromus Tectorum Cover Mapping and Fire Risk," International Journal of Wildland Fire 15:113-119.

Maher, Anna. (2007) Economic Impacts of Sagebrush Steppe Wildfires on an Eastern Oregon Ranch, Thesis, Oregon State University, Corvallis, OR.

Minnesota IMPLAN Group, Inc. (2006) IMPLAN Professional Social Accounting and Impact Analysis Software, MIG, Inc. Stillwater, Minnesota.

National Oceanic and Atmospheric Administration (NOAA). (2011) Satellite and Information Service: U.S. Climate at a Glance, available at http://lwf.ncdc.noaa.gov/oa/climate/research/cag3/cag3.html

(C) Southern Regional Science Association 2013. 
Pratt, Mindy, and Allen Rasmussen. (2001) Determining Your Stocking Rate. Range Management Fact Sheet, NR/RM/04, Utah State University Cooperative Extension.

Richardson, James, Steven Klose, Allan Gray. (2000) "An Applied Procedure for Estimating and Simulating Multivariate Empirical (MVE) Probability Distribution in Farm-level Risk Assessment and Policy Analysis," Journal of Agricultural and Applied Economics 32(2): 299-315.

US Government Accountability Office (US GAO). (2005) Livestock Grazing - Federal Expenditures and Receipts Vary, Depending on the Agency and the Purpose of the Fee Charged, Reports to Congressional Requesters, GAO-05-869, Washington, DC. 